\title{
Consulta de enfermagem em puericultura na estratégia saúde da família
}

Nursing appointments in puericulture in family health strategy

Consulta de enfermaría en puericultura en la estrategia salud de la familia

Maria Aparecida Munhoz Gaíva ${ }^{1}$ (D) https://orcid.org/0000-0002-8666-9738

Mayrene Dias de Sousa Moreira Alves ${ }^{1}$ (D) https://orcid.org/0000-0002-9397-6517

Caroline Aparecida Coutinho Monteschio ${ }^{1}$ (D) https://orcid.org/0000-0001-7636-7974

\section{Resumo}

Objetivo: Analisar as ações desenvolvidas pelo enfermeiro na consulta de puericultura à criança, em unidades de saúde da família.

Métodos: Pesquisa descritiva de abordagem qualitativa desenvolvida em Cuiabá, Mato Grosso, Brasil, com enfermeiros que realizavam consulta de enfermagem à criança de maneira programática nas unidades de saúde da família. Foram observadas 21 consultas entre janeiro e fevereiro de 2012. Os dados foram analisados pela técnica da análise de conteúdo e resultaram em três categorias: acompanhamento do crescimento e desenvolvimento; incentivo e promoção do aleitamento materno e imunização da criança.

Resultados: A observação das consultas permitiu apreender que os enfermeiros possuem conhecimento amplo dos aspectos que envolvem a atenção à saúde da criança, abordando com competência as principais linhas de cuidado infantil propostas pelas políticas ministeriais.

Conclusão: Os resultados obtidos mostraram que a maioria dos enfermeiros avalia aspectos imprescindíveis para 0 acompanhamento adequado e integral da criança.

\section{Abstract}

Objective: To analyze the actions developed by the nurse in the puericulture appointment to a child, in units of family health.

Methods: Descriptive research with qualitative approach developed in Cuiabá, Mato Grosso, Brazil, with nurses that performed the nursing appointment with a child in a programmatic way in units of family health. 21 appointments were observed between January and February 2012. The data were analyzed by the content analysis technique and resulted in three categories: monitoring of the growth and development; motivation and promotion of mother's nursing and immunization of the child.

Results: The observation of the appointments allowed to apprehend that the nurses have broad knowledge about the aspects that involve the attention to care of the child, approaching with competence the main lines of childcare proposed by ministerial politics.

Conclusion: The results obtained showed that the majority of nurses evaluate the indispensable aspects to the adequate and complete monitoring of the child.

\section{Resumen}

Objetivo: Analizar las acciones desarrolladas por el enfermero en la consulta de puericultura a el niño, en unidades de salud de la familia.

Métodos: Pesquisa descriptiva de abordaje cualitativa desarrollada en Cuiabá, Mato Grosso, Brasil, con enfermeros que realizaban consulta de enfermaría a el niño de manera programática en las unidades de salud de la familia. 21 consultas fueran observadas entre enero y febrero de 2012. Los datos fueron analizados por la técnica de la análisis de contenido y resultaron en tres categorías: seguimiento del crecimiento y desarrollo; incentivo y promoción de la lactancia materna y inmunización del niño.

Resultados: La observación de las consultas permitió arrestar que los enfermeros tienen conocimiento amplio de los aspectos que envuelven la atención a la salud del niño, abordando con competencia las principales líneas de cuidado infantil propuestas por políticas ministeriales.

Conclusion: Los resultados obtenidos muestró que la mayoría de los enfermeros evalúan aspectos imprescindibles para el seguimiento adecuado y integral del niño.

\section{Como citar:}

Gaíva MA, Alves MD, Monteschio CA. [Nursing appointments in puericulture in family health strategy]. Rev Soc Bras Enferm Ped. 2019;19(2):65-73. Portuguese

\section{Descritores}

Saúde da criança; Enfermagem pediátrica; Cuidado da criança; Atenção primaria à saúde

\section{Keywords}

Child health; Pediatric nursing; Child care; Primary health care

\section{Descriptores}

Salud del niño; Enfermería pediátrica; Cuidado del niño; Atención primaria de salud

\footnotetext{
${ }^{1}$ Universidade Federal de Mato Grosso, Cuiabá, MT, Brasil.
}

Conflitos de interesse: nada a declarar.

Submetido: 29 de Março de 2019 | Aceito: 20 de Dezembro de 2019

Autor correspondente: Mayrene Dias de Sousa Moreira Alves | E-mail: mayrenemay@hotmail.com

Dol: http://dx.doi.org/10.31508/1676-3793201900009 


\section{Introdução}

A saúde da criança representa um campo prioritário no âmbito dos cuidados à saúde das populações, em função da vulnerabilidade nessa fase da vida. ${ }^{(1)}$ Nesta perspectiva, assistir a criança implica em atender as necessidades essenciais para o seu desenvolvimento.

O acompanhamento do crescimento e desenvolvimento da criança deve ser realizado prioritariamente na Atenção Básica por meio da Estratégia Saúde da Família (ESF). ${ }^{(1)} \mathrm{O}$ enfermeiro como parte integrante da equipe multiprofissional da ESF, possui atribuições e responsabilidades com relação à saúde da criança e sua família, e vem utilizando a consulta de enfermagem (CE) como um instrumento fundamental para sua atuação junto a esse grupo populacional.

A CE em puericultura é uma estratégia importante para promoção, vigilância e acompanhamento da saúde da criança, com a finalidade de promover o aproveitamento de todo o potencial intrínseco de seu crescimento. A consulta possibilita ao enfermeiro conhecer problemas de saúde, estabelecer prioridades, prescrever os cuidados e orientar as mães, além de estabelecer vínculo, comunicação e relação interpessoal com a criança e sua família. ${ }^{(2)} \mathrm{O}$ desenvolvimento da consulta envolve sequência sistematizada de ações: histórico de enfermagem e exame físico, diagnóstico de enfermagem, plano terapêutico ou prescrição de enfermagem, e avaliação da consulta.

Pesquisa que investigou como se configura a assistência de enfermagem a crianças menores de cinco anos em unidades de saúde da família de um município paulista, evidenciou que a prática do enfermeiro envolve ações como exame físico, controle do crescimento e desenvolvimento (CD), imunização, coleta de material para exames, incentivo ao aleitamento materno, orientações para alimentação infantil e prevenção de acidentes, visita domiciliar, além de trabalho colaborativo com o médico. ${ }^{(3)}$

Apesar da CE ser atualmente uma atividade programática realizada de modo sistemático, no atendimento de puericultura nas unidades de saúde da família (USF), nem todos os enfermeiros percebem-se aptos para desenvolvê-la, sendo que alguns não realizam a consulta de modo rotineiro, por reconhecerem a necessidade de maior preparo para executá-la. ${ }^{(2)}$
Com base no exposto, e na importância da CE para prevenção, promoção e proteção da saúde da criança, esta pesquisa tem como objetivo analisar as ações desenvolvidas pelo enfermeiro na consulta de puericultura à criança em unidades de saúde da família.

\section{Métodos}

Estudo descritivo exploratório de abordagem qualitativa realizado em quatro USF do município de CuiabáMT, Brasil. Os participantes da pesquisa foram quatro enfermeiros que desenvolviam a CE como atividade programática nas unidades que atuavam.

Os dados foram coletados no período de janeiro e fevereiro de 2012, utilizando-se da observação participante de 21 consultas realizadas nas unidades selecionadas. Os critérios de inclusão para definir quais CE seriam observadas foram: consultas com mães ou familiares de crianças com idade entre 0 e dois anos, cadastrados e em acompanhamento pelas equipes das USF escolhidas para a pesquisa. A opção por observar consultas de crianças nessa faixa de idade foi por que neste período da infância as consultas são realizadas com intervalos menores, e também por que nessa idade, as crianças são mais vulneráveis e demandam maiores cuidados profissionais. O fim do trabalho de campo se deu pelos critérios de inclusão e quando observamos que as informações recolhidas das observações das consultas forneceram dados com qualidade e quantidade para responder ao objetivo do estudo. ${ }^{(4)}$

Para auxiliar a observação participante, os diálogos foram captados através de gravação em áudio, para apreender detalhes das conversas, das informações transmitidas, da interação do enfermeiro/criança/ mãe/acompanhantes, entonação de voz etc. Os dados das observações foram registrados em diário de campo e as gravações foram transcritas fidedignamente e acrescentadas aos registros contidos no diário.

Para a análise dos dados foi utilizada a técnica de analise temática, ${ }^{(5)}$ que consistiu primeiramente na pré-análise e exploração dos dados, posteriormente os achados foram organizados sistematicamente e agregados em unidades de registro, o que permitiu uma descrição exata das características pertinentes. Procedeu-se, então, à categorização que consistiu em isolar os elementos do discurso e impor certa or- 
ganização às mensagens, definindo as categorias do estudo. Para o presente artigo foram selecionadas as categorias consideradas eixo norteador da CE em puericultura: acompanhamento do $\mathrm{CD}$ infantil; incentivo e a promoção do aleitamento materno (AM) e imunização da criança.

Ressalta-se que no município estudado não há um protocolo especifico para a CE em puericultura, nem a definição de um referencial teórico-metodológico para a mesma. Assim cada enfermeiro desenvolve a consulta com a metodologia que tem mais domínio. Apesar de não ter sido objeto desta pesquisa avaliar a metodologia utilizada pelos enfermeiros, destaca-se que todas as consultas observadas contemplaram as etapas básicas preconizadas: histórico/anamnese, exame físico, detecção de problemas, plano de cuidados e ações educativas.

Este estudo foi aprovado pelo Comitê de Ética em Pesquisa do Hospital Júlio Müller, protocolo no 129/ CEP-HUJM/2011, respeitando todos os preceitos éticos previstos na Resolução 466/2012. Os enfermeiros e as mães ou responsáveis pelas crianças foram informadas sobre a pesquisa e aquelas que concordaram em participar assinaram o Termo de Consentimento Livre e Esclarecido. Para resguardar a identidade dos participantes e das unidades, os relatos do diário de campo foram identificados apenas com o número da consulta.

\section{Resultados}

\section{Acompanhamento do crescimento e desenvolvimento infantil}

Todas as crianças observadas foram avaliadas com relação ao crescimento, sendo que as ações dos enfermeiros voltadas à promoção do crescimento infantil foram: avaliação e registro dos índices antropométricos, peso para idade, estatura para idade e perímetro cefálico (PC) para a idade e índice de massa corporal (IMC). Ressalta-se que as medidas antropométricas eram realizadas pelos técnicos em enfermagem na sala de pré-consulta, exceto o PC, que era aferido pelo enfermeiro durante a avaliação física da criança.

O histórico de ganho e perda de peso e sua relação com a idade foi uma preocupação dos enfermeiros nas consultas observadas, bem como o crescimento compensatório:

Enfermeira - É ela já tá com 8.900 gramas. O peso dela também está bom, tá ótimo, tá ganhando peso. Então, você não precisa se preocupar tá? Olha só por isso que eu falo que ela tá comendo pouco, olha só aqui tem uma quedinha (apontando para o gráfico de peso na caderneta), mesmo assim ela não está em risco, olha aqui a linha vermelha, ela está ganhando pouco peso, mas está tudo dentro do normal (Consulta 3).

Enfermeira - Quando ela estava amamentando no peito ela não estava abaixo da curva, mas aí ela começou a baixar quando da introdução $e$ (fala sobre a introdução dos alimentos), saída do peito.

Mãe - Mas e agora enfermeira?

Enfermeira - Vamos consultar todo mês e levantar o peso dela (Consulta 20).

Observou-se também a preocupação dos enfermeiros em explicar para mãe a necessidade de avaliar o PC da criança:

Enfermeira - Olha só, aqui nós vamos marcar o PC dela porque o corpo cresce e o crânio também cresce [...] Se o crânio não desenvolve com a idade, ele pode estar desenvolvendo uma doença. Se ele também cresce, digamos assim, acima do esperado para a idade, também há indícios que precisa fazer uma avaliação médica para ver se não tem nenhuma doença, alguma patologia, certo? (Consulta 15).

Outro índice antropométrico importante para a avaliação do crescimento infantil é o IMC. Observou-se que este índice ainda não é utilizado rotineiramente nas $C E$, já que foi verificado apenas por um dos enfermeiros:

Enfermeira - Ele está meio gordinho, mas também está alto, então ele não fica com aquela aparência de gordo. Ele está com IMC normal (Consulta 9).

Nem todas as crianças acompanhadas tiveram o seu desenvolvimento avaliado na consulta. Naquelas que foram avaliadas, os enfermeiros coletavam informações com as mães, mas não observavam ou testavam os marcos do desenvolvimento no exame físico da criança.

Das 21 crianças observadas, 14 tiveram seu desenvolvimento verificado de alguma forma pelo enfermeiro. Em oito consultas foi empregado o instrumento de vigilância do desenvolvimento da caderneta de saúde da criança (CSC), em três o enfermeiro utilizou o teste de Denver II e nas outras três crianças apenas foi questionado à mãe se alguns marcos do desenvol- 
vimento estavam presentes, mas sem usar nenhum instrumento específico.

O instrumento mais utilizado para avaliação do desenvolvimento da criança foi a CSC:

Enfermeira - Sorri e conversa com a criança, ao mesmo tempo que pergunta para a mãe se a criança abre e fecha a mão sozinha.

Enfermeira - [...] E deixa eu te falar, quando você está conversando com ela, ela fica repetindo com você? Assim, conversa junto?

Mãe - Aham

Enfermeira - Já segura alguma coisa com a mãozinha? Mãe - Segura.

Enfermeira - O desenvolvimento dela está normal (Consulta 7).

Enfermeira - Então ela está desenvolvendo sim, você já viu ela virando a cabecinha?

Mãe - Sim, para os dois lados.

Enfermeira - Você já a colocou de bruços, de barriguinha para baixo?

Mãe - Não.

Enfermeira - Ainda não, né? Mas com um mês a gente vai fazer esse teste nela tá? Você já percebeu algum sorriso dela?

Mãe - Já.

Enfermeira - Abre e fecha as mãos, sozinha? Ela emite algum som que não seja choro? Você já ouviu algum sonzinho da boca dela, que não fosse choro? (Mãe responde positivamente com a cabeça). Ela está bem espertinha, tá bom? Desenvolvimento ótimo! (Consulta 2).

Outro instrumento utilizado para avaliar o desenvolvimento da criança foi o teste de Denver II:

Enfermeira - (com o formulário do teste de desenvolvimento de Denver em mãos) indaga: Ela está com um ano e 6 meses, né? Já tem que fazer alguma coisa, ajudando você, por exemplo, se você está limpando casa, varrendo, ela pega essa vassoura para te ajudar? Brincando?

Mãe - Pega.

Enfermeira - Come sozinha, que você já me falou, né? [...] E se você der algum papel para ela, ela rabisca, tenta desenhar, escrever alguma coisa?

Mãe - Rabiscar ela rabisca.

Enfermeira - Quantas palavras ela já sabe falar? Você sabe me dizer?

Mãe - Ah algumas.

Enfermeira - Muito bem! Bom, como eles costumam falar, ela passou no teste de Denver. (Risos) Teste de Denver normal, foi aprovada! (Consulta 19).
Destaca-se, que nenhuma das crianças examinadas apresentou alterações no desenvolvimento. No entanto, em poucas situações observadas o enfermeiro orientou a mãe a estimular a criança ou indicou atividades de recreação/brincadeiras de acordo com a fase de desenvolvimento da mesma.

A CSC foi utilizada por todos os enfermeiros como instrumento para avaliação do crescimento infantil e orientações às mães:

Enfermeira - (mostrando a CSC para a mãe) Você tem uma caderneta ou cartilha que é importantíssima! Tem além das orientações de higiene, alimentação, o gráfico de crescimento e desenvolvimento da criança, que nos mostram se está dentro de um padrão normal e as vacinas (Consulta 16).

Os recortes do diário de campo evidenciaram que os enfermeiros além de preencher os gráficos de crescimento na caderneta também orientam as mães a interpretá-los:

Enfermeiro - Todos os gráficos que tem nessa caderneta têm várias linhas traçadas de cores. Olha só. Então, os valores de medidas que foi feito, de peso, altura, a circunferência da cabeça, que a gente chama de perímetro cefálico, tem que estar na proximidade dessa linha verde ou um pouquinho acima, ou na linha dela, um pouquinho inferior, não pode, pelo menos não se aceita que possa estar acima dessa linha vermelha ou abaixo dessa vermelha. Tá certo? Se tiver acima ou abaixo da linha vermelha, fora do caminho da saúde algo deve estar errado, é preciso investigar (a mãe escuta atentamente o que o enfermeiro está dizendo, balançando a cabeça como resposta positiva, dizendo "aham"). Então, aqui é um exemplo prático, que você mãe pode estar olhando e verificando se as medidas do seu filho, conforme a idade dele, estão adequadas ou não (Consulta 16).

Enfermeiro - Então, olha só. Ela está com dois meses e 5,900 gramas. A linha da saúde, a linha verde, está ok? (Mostra para mãe os pontos no gráfico da CSC) [...]. Essa linha verde é de referência para qualquer valor desse ai. Seja para perímetro cefálico, da cabeça, altura ou peso. Vamos ver agora a altura, o comprimento, a idade. Deu 58 centímetros. Olha aí, perto da linha (mostra o gráfico para a mãe) (Consulta 15).

Outro ponto a ser ressaltado foram as orientações realizadas pelos enfermeiros às mães quanto a importância do acompanhamento contínuo da criança, bem como, sobre o cronograma das consultas de puericultura nas USF do município: 
Enfermeira - Mãe, você está fazendo a primeira consulta que a gente preconiza com 15 dias. Quando ela fizer um mês tem outra consulta. Aqui você vai ter o acompanhamento e todo o mês você consulta. Por quê? Para fortalecer os seus cuidados com a criança, para você tirar suas dúvidas e para você saber se a criança está desenvolvendo bem (Consulta 8).

\section{Incentivo e promoção ao aleitamento materno}

Os enfermeiros abordaram o aleitamento materno em todas as consultas, especialmente com as mães de crianças menores de seis meses, que deveriam estar em aleitamento materno exclusivo (AME). As principais ações desenvolvidas foram de incentivo e promoção; abordagem clínica do aleitamento e atuação frente ao desmame precoce.

Para estimular o AME os enfermeiros orientavam as mães sobre a sua importância nos primeiros seis meses de vida da criança:

Enfermeira - $O$ aleitamento materno é muito importante nos primeiros seis meses de vida da criança[...]. Ele que fortalece, é o que nutre, é o que faz a criança se desenvolver [...] (Consulta 8 ).

Enfermeiro - [...] leite materno em livre demanda, nos primeiros seis meses de vida é única e exclusivamente o leite materno. Não há necessidade de outra coisa, de outro alimento, a não ser o leite materno porque ele tem nutrientes essenciais e importantes para a tua filha. Desde água, nutrientes, vitaminas, que você passa através do leite, são os anticorpos ou defesas, que ela absorve e outras substâncias importantes para o seu crescimento e desenvolvimento. Isso é de relevante importância (Consulta 15)

A orientação sobre a técnica de amamentação também foi uma preocupação manifestada pelos enfermeiros:

Enfermeira - Nunca a deixe mamar com a boquinha só pegando o bico, a boca tem que pegar a aréola todinha, abrir a boca e abocanhar não só o biquinho. Entendeu? Barriguinha com barriguinha. Deve ser por isso que está ferindo. A boquinha tem que abrir. O importante é não desistir, sofre um pouquinho, mas a tendência é sarar (Consulta 8).

Enfermeiro - Como é que eu dou de mamar? Eu dou um seio, quando ele esvaziar, eu dou o outro, se ele não esvaziar e ela já se encheu você vai voltar nele na próxima mamada. Por quê? O leite, ele não é todo igual do começo ao fim da mamada, na hora que ela começou a mamar o leite que vem, é diferente, tem mais proteína, tem os anticorpos, que tem os nutrientes para ela. Já no final ele vem com mais gordura que vai fazê-la engordar. Então, ela precisa do leite do começo ao fim da mamada (Consulta 11).

Na situação de desmame precoce, a atuação dos enfermeiros foi focada em orientações para manter o AME nos primeiros seis meses de vida da criança; desencorajar o uso de outros leites e mamadeiras e sugerir alternativas para que as mães continuassem com o AME, mesmo após o retorno ao trabalho:

Enfermeira - Se de repente acontecer de você precisar sair e acontecer alguma coisa, e aí você tiver que dar outro leite, até nisso a gente não recomenda outro leite, a gente sempre orienta a mãe a tirar o próprio leite e armazenar no congelador. A gente recomenda dar leite no copinho, tá? Não é para dar mamadeira (Consulta 2).

Enfermeira - Outra coisa que eu te falo, é a ordenha,é você tirar o seu leite para dar para criança quando você não estiver em casa. Então, a gente fala muito isso, dá trabalho, mas tem mãe que consegue fazer isso, para você diminuir essas mamadeiras durante o dia (Consulta 7).

Enfermeira - T. (nome da mãe) igual eu já te falei antes, ele tem uma forte tendência a largar o peito, a criança tem uma preferência pela mamadeira, ela fica confusa com relação ao bico do peito e ao bico da mamadeira. Você consegue manter ele no peito? (Consulta 1).

A enfermeira alerta a mãe sobre seus direitos como lactante e orienta como deve proceder para manter a amamentação:

Enfermeira - Você tem direito a sair uma hora antes para amamentar, você conversa isso com ele (refere-se ao empregador). [...] Na verdade, é assim, meia hora no primeiro horário e meia hora no segundo horário (Consulta 7).

\section{Imunização da criança}

As orientações sobre a importância das vacinas para a criança foram observadas em todas as consultas:

Enfermeira - Vacina é muito importante. Antigamente a gente não tinha tanta vacina disponível, e tinha mais mortes de crianças por doenças que dava para evitar, então é preciso realmente dar as vacinas, afinal a gente tem aqui no posto, e é perto da sua casa (Consulta 10)

Enfermeiro - Não esquecer das vacinas, elas são fundamentais para a criança! (Consulta 5).

Os enfermeiros avaliaram sistematicamente o calendário vacinal da criança em todas as consultas, 
orientando as mães sobre quais as vacinas e a idade que a criança iria tomar:

Enfermeira - Estão todas as vacinas aqui agendadas (enquanto vai falando vai indicando com o dedo no calendário), pneumo, meningo, ela tomou com dois meses (fala da vacina pneumocócica) agora vai tomar com três mês (fala da meningocócica $C$ apontando também para o local de agendamento na caderneta), vai tomar com quatro, vai tomar com cinco, todo mês ela tem vacina (Consulta 6).

Enfermeiro - [...] vacinas, ele tem a vacina de nove meses que ele já tomou e a próxima vacina é com um ano, a tríplice viral, para não esquecer sarampo, rubéola e caxumba (risadas). É! Tem os reforços com um ano e três meses, são quatro reforços tá (Consulta 14).

O enfermeiro além de avaliar se as vacinas estavam em dia, orientava as mães sobre as possíveis reações vacinais:

Enfermeiro - (avalia a situação vacinal na CSC) Tomou as duas vacinas e uma é a BCG.

Mãe - Aham.

Enfermeiro - (Enfermeiro inclina-se e observa o braço direito da criança, no intuito de avaliar as reações locais da vacina BCG) [...] A cicatriz está ok, deixa eu ver, a papulazinha está formando, daqui a pouco vai romper viu, não precisa passar nada no local (Consulta 16).

Ressalta-se que foram observadas poucas orientações sobre as finalidades das vacinas, vias de administração, eventos adversos e cuidados pós-vacinal, além disso, nenhum enfermeiro procurou saber quais os conhecimentos que as mães possuíam sobre as vacinas.

\section{Discussão}

Um aspecto bem evidenciado nas observações realizadas no presente estudo foi que a CE vem sendo utilizada pelos enfermeiros da ESF como um importante instrumento para o acompanhamento do crescimento e desenvolvimento infantil, atendendo assim, as diretrizes e metas definidas pelo Ministério da Saúde $(\mathrm{MS}),{ }^{(1)}$ no que se refere à saúde da criança, tal como já observado em outras pesquisas. ${ }^{(6)}$

O acompanhamento do CD é uma oportunidade para o profissional analisar de forma integrada e preditiva a saúde da criança, pois possibilita ações de cuidado que visam o seu desenvolvimento de maneira saudável e a prevenção precoce de agravos de sua saúde, ${ }^{(6)}$ já que o crescimento é um importante indicador das condições de saúde e da qualidade de vida infantil, por sua estreita relação com os aspectos socioeconômicos, ambientais e culturais da população. (7) Destaca-se que a avaliação do crescimento pode ser realizada a partir da história clínica e social, exame físico, dados dos pais e pelos parâmetros do crescimento físico nas diferentes etapas da vida da criança.

Por sua vez, o acompanhamento do desenvolvimento infantil constitui uma modalidade de vigilância do processo saúde/doença, que abarca atividades relacionadas à promoção do desenvolvimento normal e à detecção de alterações neste processo, sendo um dos principais objetivos da atenção primária à saúde da criança. ${ }^{(8)}$

Apesar da relevância do acompanhamento do CD infantil, as pesquisas na área da saúde mostram que existe um sério problema de baixa sensibilização dos profissionais para sua efetivação na prática, acarretando falhas no processo de assistência à saúde infantil. ${ }^{(8)}$ As pesquisas mostram ainda, pouca valorização das informações relacionadas ao desenvolvimento infantil por parte dos profissionais de saúde, evidenciada pela ausência ou incompletude dos registros na CSC ou nos prontuários. ${ }^{(9,10)}$

Revisão de literatura sobre a vigilância do crescimento no contexto da Rede Básica de Saúde do SUS mostrou como problemas mais frequentes no atendimento de puericultura na realidade brasileira, a subutilização da CSC em relação ao registro das medidas de crescimento e à adoção de orientações sob a base das anotações realizadas. ${ }^{(11)}$

Apesar da qualidade do acompanhamento do CD infantil de não ter sido objeto desta pesquisa, foi possível observar que nem todos os enfermeiros participantes realizaram a avaliação do desenvolvimento, e mesmo aqueles que o fizeram, não o efetivaram conforme se preconiza, uma vez que só perguntavam para as mães se os marcos do desenvolvimento para a idade estavam presentes, mas não checavam por meio do exame da criança se estes estavam realmente presentes. Resultado semelhante foi verificado em pesquisa que analisou a consulta de enfermagem em puericultura em município no oeste do Paraná, constatando também que os marcos do desenvolvimento não foram registrados na CSC. ${ }^{(7)}$ Além disso, não 
se observou nas consultas analisadas a realização de orientações sobre os fatores que interferem nesse processo e nem tampouco, a proposição de atividades para estimulá-lo.

A estimulação para a promoção do desenvolvimento da criança constitui-se um dos cuidados básicos para saúde física, mental, psíquica e social da criança. Recomenda-se, que o profissional observe movimentações, linguagem, comportamentos, relação e estímulo materno, além de testar a presença ou não destes marcos durante a conversa com a mãe e no exame físico da criança. (1) Todavia, para que o enfermeiro faça a avaliação do desenvolvimento da criança é necessário que ele conheça os instrumentos e os marcos descritos para cada faixa etária, pois este conhecimento facilita a avaliação e a detecção de alterações importantes que requerem intervenções e acompanhamento especializado da criança

O Ministério da Saúde considera o acompanhamento do CD infantil como eixo norteador da atenção integral à saúde da criança na atenção primária, e define que este deve envolver ações de vigilância em saúde, avaliação dos índices antropométricos, desenvolvimento, imunização vacinação e controles dos agravos à saúde, além de incluir aspectos relativos à alimentação, higiene e estimulação em todo o atendimento ofertado à criança, bem como, o registro sistemático na CSC.(1) Aspectos estes que foram observados nas consultas do presente estudo.

As observações realizadas nesta pesquisa evidenciaram que os enfermeiros da ESF atendem as crianças de maneira programática, de acordo com o calendário mínimo de consultas estabelecido pelo Ministério da Saúde na CSC para o acompanhamento do estado de saúde da criança, principalmente com relação ao $\mathrm{CD}^{(1)}$. $\mathrm{O}$ seguimento do calendário de consultas à criança pode ser considerado um indicador da qualidade da atenção prestada pelos serviços de saúde.

Ao observar as CE à criança verificou-se o papel decisório do enfermeiro na promoção e proteção do AM. O incentivo ao AME foi uma das principais preocupações do enfermeiro durante as consultas, sendo que todas as mães de crianças menores de seis meses atendidas pelos enfermeiros foram incentivadas a manter o aleitamento materno exclusivo. Sabe-se que este nos primeiros seis meses de vida tem reflexos diretos no aumento da resistência imu- nológica, estado nutricional e emocional da criança, além de melhorar a autoconfiança das mães em sua capacidade de amamentar. ${ }^{(12,13)}$

A preocupação dos enfermeiros com o AM pode ser justificada pelo fato que a maior parte das crianças menores de seis meses estava em processo de desmame precoce. Dentre as causas do desmame referidas pelas mães aos enfermeiros, destacaram-se: retorno ao trabalho; uso de bicos, chupetas e mamadeiras, concepção de que seu leite era fraco e insuficiente, dentre outras. Pesquisa realizada em Santo Antônio do Monte- Minas Gerais (Brasil) que objetivou investigar os fatores relacionados ao desmame precoce antes dos seis meses de vida, mostrou que dentre estes estavam: crença quanto ao leite fraco ou insuficiente para o bebê, má interpretação do choro do bebê, inexperiência ou insegurança da mãe e volta ao trabalho. A atuação/ profissional também se destacou como um fator determinante para o problema. ${ }^{(14)}$

Como se pode ver, comprovadamente as mães carecem de conhecimento e apoio para desenvolver a prática do AM. Apoio este, que pode ser oferecido pelo enfermeiro na consulta e durante todo o processo de amamentação, notadamente nos primeiros meses de vida da criança. Ainda, há que se considerar que o incentivo e apoio ao AM deve incluir a avaliação técnica, seu manejo, orientações sobre os benefícios do aleitamento para a mãe e para o bebê, e os direitos da criança ao aleitamento e os direitos da nutriz.

O leite materno não deve ser substituído pelo uso de leite artificiais, chupetas ou mamadeiras, pois estes prejudicam a criança em diversos aspectos, principalmente no seu crescimento e desenvolvimento. $\mathrm{O}$ uso de mamadeira, além de ser uma fonte de contaminação para a criança pode influenciar negativamente na amamentação. ${ }^{(15)}$ Crianças que são desmamadas precocemente possuem maior risco de doenças e taxa de mortalidade mais elevada, assim como maior incidência de anemia, internações por doenças diarreicas e pneumonia. ${ }^{(16)}$ Assim, o profissional de saúde capacitado é ator importante neste cenário para apoiar a nutriz e sua família no processo de amamentação. ${ }^{(12)}$

Observou-se na presente pesquisa, que a maioria dos enfermeiros realizou orientações sobre amamentação, desmame precoce e alimentação complementar da criança, conforme preconizado pelo Ministério da Saúde. Durante a consulta de puericultura o enfermei- 
ro não deve perder de vista a importância das ações educativas, com vistas a promoção da saúde e incentivo às mães para o cuidado com seus filhos. ${ }^{(6)}$ No acompanhamento de puericultura, a alimentação da criança deve ser um dos focos do cuidado do enfermeiro, que perpassa pelo incentivo ao AME, orientações para introdução de alimentos complementares, além do apoio a mãe e família para esta prática.

A imunização infantil é uma das ações de saúde primordiais e que apresentou maior evolução no campo da saúde pública, nos últimos anos. A vacinação é uma prática presente na rotina dos serviços de atenção primária à saúde e tem influência direta nas condições gerais de saúde da criança, proporcionando maior possibilidade de um crescimento e desenvolvimento saudável, além de contribuir significativamente para a redução da mortalidade infantil por doenças preveníveis. ${ }^{(1)}$ Para tal, o Ministério da Saúde estabelece um calendário vacinal infantil básico e disponibiliza em todo território nacional esses imunobiológicos.

Considerando que a imunização é um meio protetor de grande importância para a população infantil, o monitoramento da situação vacinal é de extrema relevância na avaliação das condições de saúde da criança. Neste sentido, a observação das consultas mostrou que os enfermeiros além de orientarem as mães sobre a importância da imunização, conferiam as vacinas já administradas, informavam sobre os agendamentos e encaminhavam a mãe para a sala de vacinação se tivesse vacinas a serem feitas, não perdendo nenhuma oportunidade para imunizar a criança. Situação essa que também foi observada em pesquisa que analisou a consulta de puericultura de enfermeiros no Paraná.( ${ }^{(7)}$

O papel do enfermeiro na prática da imunização é essencial, bem como dos outros membros da equipe de enfermagem, especialmente como educadores, transmitindo informações referentes à prevenção de doenças, contribuindo para que as famílias percebam o valor das vacinas. Assim sendo, estes profissionais precisam possuir conhecimento sobre a importância da imunização, manuseio das vacinas e o calendário atualizado de imunobiológicos.

Todavia, para que as mães ou responsáveis pelas crianças tenham conhecimento da importância das vacinas, é imprescindível que as informações prestadas pelos profissionais de enfermagem sejam de fácil entendimento, além de possibilitar a participação das mães no processo de comunicação para que estas esclareçam suas dúvidas. Estudo que investigou o conhecimento de mães sobre o esquema vacinal de seus filhos assistidos em uma Unidade Básica de Saúde, evidenciou que informações e comunicação clara entre mães e profissionais são fundamentais para promover o cumprimento do calendário vacinal na infância. ${ }^{(17)}$

Dessa forma, reafirma-se que a imunização infantil não se restringe apenas a aplicação dos imunobiológicos, mas também envolve ações de educação em saúde e as relações entre os profissionais de saúde e as crianças e mães.

Considerando que a Puericultura é fundamental para a promoção da saúde da criança e se desenvolvida de forma adequada pelo enfermeiro, previne doenças e agravos a saúde infantil, questionamos: será que as ações de cuidados desenvolvidas pelos enfermeiros na consulta de puericultura em diferentes contextos assistenciais do país são semelhantes? Acreditamos que sim e, apesar dos dados dessa pesquisa terem sido coletados no ano de 2012, o panorama encontrado hoje não é diferente, como evidenciam as investigações realizadas no nordeste e no sul do país. ${ }^{(7,18)}$ O que reforça a necessidade de novos estudos, a fim de apontar estratégias para sanar as inadequações e para que a consulta do enfermeiro contribua para a almejada integralidade na assistência à criança.

Como uma limitação do estudo destaca-se a abordagem metodológica descritiva, que permite identificar a realidade, mas necessita de outros aportes para maior detalhamento do objeto. Além disso, os resultados aqui apresentados são parte de uma realidade especifica e representam apenas a visão dos pesquisadores e não dos envolvidos na consulta de puericultura. Assim, sugere-se que outros estudos avaliem a qualidade das ações desenvolvidas na consulta de enfermagem, sobretudo na visão dos enfermeiros e das mães/famílias, com o intuito de melhor conhecer esse trabalho e, desta forma, contribuir para mudanças na atenção à saúde prestada à população infantil.

\section{Conclusão}

A observação das CE à criança possibilitou apreender que os enfermeiros possuem conhecimento amplo dos aspectos que envolvem a atenção à saúde infan- 
til, e abordam com competência as principais linhas de cuidado propostas pelas atuais políticas ministeriais. A promoção do crescimento infantil foi observada em todas as consultas de enfermagem, através da avaliação dos índices antropométricos e curvas de crescimento contidas na caderneta de saúde da criança. Contudo, a avaliação e a vigilância do desenvolvimento da criança foram realizadas parcialmente na maioria das consultas, utilizando-se apenas da percepção materna sobre os marcos do desenvolvimento. Os enfermeiros abordaram aspectos importantes do aleitamento materno durante as consultas, mostrando domínio no manejo clinico da amamentação e atuaram em prol da promoção e estímulo ao AME. A imunização da criança foi observada em todas as consultas pela avaliação do calendário vacinal; identificação de esquemas vacinais atrasados; aprazamento de vacinas; encaminhamento das crianças para a sala de imunização e orientações pontuais sobre as vacinas do calendário básico e as vias e locais de administração das mesmas. Os resultados obtidos na pesquisa são relevantes, uma vez que evidenciam que a maioria dos enfermeiros implementa em sua prática da consulta de puericultura, a avaliação de aspectos imprescindíveis para o acompanhamento adequado e integral à criança.

\section{Contribuições}

\author{
Gaíva MAM, Alves MDSM e Monteschio CAC \\ declaram que contribuíram com a concepção do \\ estudo, análise e interpretação dos dados, reda- \\ ção do artigo, revisão crítica relevante do conteú- \\ do intelectual e aprovação da versão final a ser \\ publicada.
}

\section{Referências}

1. Brasil. Ministério da Saúde. Secretaria de Atenção à Saúde. Departamento de Ações Programáticas Estratégicas. Política nacional de atenção integral à saúde da criança: orientações para implementação. Brasília (DF): Ministério da Saúde; 2018.

2. Benicio AL, Santana MD, Bezerra IM, Santos RR. Cuidado a criança menor de um ano: perspectiva da atuação do enfermeiro na puericultura. Rev Enferm UFPE. 2016;10(2):57684.

3. Furtado MC, Mello DF, Pina JC, Vicente JB, Lima PR, Rezende VD. Ações e articulações do enfermeiro no cuidado da criança na atenção básica. Texto Contexto Enferm. 2018;27(1):e0930016.

4. Malterud K, Siersma VD, Guassora AD. Sample size in qualitative interview studies: guided by information power. Qual Health Res. 2016;26(13):1753-60.

5. Bardin L. Análise de conteúdo. Lisboa: Edições 70; 2011.

6. Brito GV, Albuquerque IM, Ribeiro MA, Ponte EC, Moreira RM, Linhares MG. Consulta de puericultura na Estratégia Saúde da Família: percepção de enfermeiros. Rev APS. 2018;21(1):48-55.

7. Faller $\Pi$, Toso BR, Viera CS, Baggio MA. A consulta de enfermagem em puericultura na estratégia saúde da família. Rev Varia Scientia. 2018;4(2):137-46.

8. Almeida AC, Mendes LC, Sad IR, Ramos EG, Fonseca VM, Peixoto MV. Uso de instrumento de acompanhamento do crescimento e desenvolvimento da criança no Brasil - revisão sistemática de literatura. Rev Paul Pediatr. 2016;34(1):122-31.

9. Caminha MF, Silva SL, Lima MC, Azevedo PT, Figueira MC, Batista Filho M. Vigilância do desenvolvimento infantil: análise da situação brasileira. Rev Paul Pediatr. 2017;35(1):102-9.

10. Reichert AP, Vieira DS, Santos NC, Albuquerque TM, Collet N, Vaz EM. Vigilância do crescimento e desenvolvimento: análise dos registros na caderneta de saúde da criança. Cogitare Enferm. 2016;21(4):1-9.

11. Pedraza DF. Vigilância do crescimento no contexto da Rede Básica de Saúde do SUS no Brasil: revisão da literatura. Rev Bras Saúde Matern Infant. 2016;16(1):7-19.

12. Silva EP, Silva ET, Aoyama EA. A importância do aleitamento materno nos seis primeiros meses de vida do recém-nascido. ReBIS. 2020;2(2):60-5.

13. United Nations Children's Fund (UNICEF), World Health Organization (WHO). Capture the moment: early initiation of breastfeeding: the best start for every newborn. New York: UNICEF; 2018.

14. Andrade HS, Pessoa RA, Donizete LC. Fatores relacionados ao desmame precoce do aleitamento materno. Rev Bras Med Fam Comunidade. 2018;13(40):1-11.

15. Brasil. Ministério da Saúde. Secretaria de Atenção à Saúde. Departamento de Atenção Básica Saúde da Criança. Saúde da criança - aleitamento materno e alimentação complementar. Brasília (DF): Ministério da Saúde; 2015.

16. Frota MA, Lopes MF, Lima KF, Sales CO, Silva AC. Interfaces of the discontinuation of breastfeeding. Acta Sci Health Sci. 2016;38(1):33-8.

17. Cordeiro EL, Silva LS, Urquiza JL, Nascimento MA, Silva RM, Souza GC, et al. Conhecimento das mães sobre 0 esquema vacinal de seus filhos assistidos em uma unidade básica de saúde. Braz J Hea Rev. 2019;2(1):644-60.

18. Vieira DS, Santos NC, Nascimento JA, Collet N, Toso BR, Reichert AP. A prática do enfermeiro na consulta de puericultura na Estratégia Saúde da Família. Texto Contexto Enferm. 2018;27(4):e4890017. 